\title{
De effectiviteit van Eigen Kracht-conferenties in de jeugdzorg
}

\author{
Sharon Dijkstra · Hanneke Creemers · Jessica Asscher . \\ Maja Deković · Geert Jan Stams
}

\section{Samenvatting}

Op 15 mei 2019 verdedigde Sharon Dijkstra haar proefschrift, getiteld Balancing the scale of responsibility: The effectiveness of family group conferencing in child welfare. Vijf jaar lang hebben de auteurs, in samenwerking met de Eigen Kracht Centrale en Jeugdbescherming Regio Amsterdam, onderzoek gedaan naar de effectiviteit van Eigen Kracht-conferenties bij gezinnen betrokken bij Jeugdbescherming Regio Amsterdam. Dit artikel geeft een overzicht van de belangrijkste onderzoeksresultaten.

\section{Het jeugdzorgbeleid in Nederland}

Op grond van de roep om meer effectiviteit is de visie op de jeugdzorg gedurende de afgelopen decennia drastisch veranderd. Vanaf 1990 is de focus verlegd van een probleemgerichte benadering naar een oplossingsgerichte benadering, waarmee wordt getracht gezinnen meer in hun eigen kracht te zetten (Denktank Transformatie Jeugdstelsel 2014; Hoek 2010).

De oplossingsgerichte benadering zet in op het versterken van eigen krachten en stimuleert de eigen verantwoordelijkheid, waarbij actief gebruik wordt gemaakt van het sociale netwerk van het gezin. De gedachte hierachter is dat gezinnen gemotiveerder zijn om samen te werken met jeugdzorginstanties wanneer zij het gevoel hebben zelf, gesteund door hun sociale netwerk, beslissingen te kunnen nemen. De oplossingsgerichte benadering wordt ook ingezet vanuit de gedachte dat het ondersteunen van gezinnen door het aanwenden van het sociale netwerk ertoe leidt dat de behoefte aan professionele zorg (gedeeltelijk)

Dr. S. Dijkstra $(\bowtie)$

Amsterdam, Nederland

e-mail: sharon_dijkstra@live.nl

Dr. H. Creemers · Prof. dr. J. Asscher · Prof. dr. G.J. Stams

Forensische Orthopedagogiek, Universiteit van Amsterdam, Amsterdam, Nederland

Prof. dr. J. Asscher

Child and Adolescent Studies, Universiteit Utrecht, Utrecht, Nederland

Prof. dr. M. Deković

Clinical Child and Family Studies, Universiteit Utrecht, Utrecht, Nederland

Jeugdbeleid (2019) 13:211-218, https://doi.org/10.1007/s12451-019-00220-z

(C) Bohn Stafleu van Loghum is een imprint van Springer Media B.V.,

Published online: 25 October 2019 
wordt ondervangen. De verwachting is dat dit leidt tot kostenbesparingen in de jeugdzorg (MacLeod en Nelson 2000; Pagée 2012). Als gevolg van deze focusverlegging hebben methodieken gericht op versterking van de eigen kracht van gezinnen een belangrijke positie verworven in de jeugdzorg.

Een Eigen Kracht-conferentie (EKC), een Nederlandse variant van familienetwerkberaden of Family Group Conferencing, wordt in de jeugdzorg ingezet als besluitvormingsmodel om gezinnen en hun netwerk in hun kracht te zetten (voor meer informatie over deze werkwijze, zie de website: www.eigen-kracht.nl). Waar doorgaans de jeugdbeschermer, in samenwerking met het gezin, de leiding neemt bij het opstellen en het uitvoeren van een plan om problemen in het gezin aan te pakken, wordt binnen het model van de EKC de verantwoordelijkheid gelegd bij het gezin en zijn sociale netwerk.

De methodiek van de EKC bestaat uit vier verschillende fases. In de eerste fase, de verwijzing, introduceert de jeugdbeschermer de EKC in het gezin als alternatieve methode om een hulpverleningsplan op te stellen. Wanneer het gezin hiermee akkoord gaat, wordt een onafhankelijke Eigen Kracht-coördinator (EK-coördinator), die niet betrokken is bij de hulpverlening, gekoppeld aan het gezin. Hierop start de tweede fase van de EKC, de voorbereidingsfase. In deze fase bezoekt de EK-coördinator het gezin, wordt het sociale netwerk in kaart gebracht en wordt de conferentie voorbereid. In de conferentiefase wordt vervolgens het EKC-plan opgesteld. De conferentiefase start met een informatief gedeelte, waarin de professionals, inclusief de betrokken jeugdbeschermer, informatie delen over de krachten en problemen van het gezin. Deze informatie is belangrijk om te hebben voor de leden van het sociale netwerk die meedenken over de aanpak van de problemen. Wanneer er sprake is van een ondertoezichtstelling in het gezin worden er ook kaders opgesteld waaraan de doelen in het plan moeten voldoen. Na het afronden van het informatieve gedeelte stellen het gezin en het sociale netwerk in een besloten gedeelte, dus zonder de professionals, een plan op. In de presentatiefase wordt dit plan vervolgens gepresenteerd aan de professionals, waarbij de jeugdbeschermer moet instemmen met het plan. Na de conferentie start de laatste fase van de EKC: de implementatiefase. In deze fase wordt het opgestelde plan uitgevoerd, gecoördineerd door het gezin en het sociale netwerk.

Hoewel de EKC in toenemende mate wordt ingezet in de jeugdzorg is er nog weinig bewijs voor de effectiviteit van dit besluitvormingsmodel (Frost et al. 2014). Het doel van het promotieonderzoek was om bij te dragen aan de wetenschappelijke kennis over de effectiviteit van de EKC in de jeugdzorg. In de volgende paragrafen nemen we u mee in de opzet en de resultaten van de verschillende onderzoeken die we in dit kader hebben uitgevoerd.

\section{Een overzicht van de literatuur}

Aan het begin van het onderzoeksproject hebben we een overzicht gemaakt van de resultaten van familienetwerkberaden in de jeugdzorg op basis van wat bekend is uit de nationale en internationale literatuur. 'Familienetwerkberaden' is de overkoepelende benaming van de methodiek waarbij gezinnen met hun sociale netwerk een eigen hulpverleningsplan maken. Een Eigen Kracht-conferentie is hier één vorm van. In totaal werden 14 studies, met in totaal 88.495 participanten, gevonden waarin de uitkomsten van familienetwerkberaden in de jeugdzorg werden vergeleken met de uitkomsten van de reguliere werkwijze. Het ging hierbij om de volgende uitkomsten: meldingen van kindermishandeling, uithuisplaatsingen en het afsluiten van het dossier bij jeugdzorg. 
Uit de resultaten kwam naar voren dat de inzet van familienetwerkberaden, in vergelijking met de reguliere werkwijze, niet leidde tot

1. minder meldingen van kindermishandeling;

2. minder en kortere uithuisplaatsingen;

3. het eerder kunnen afsluiten van het dossier bij jeugdzorg.

Uit studies met een retrospectief design (een zwakker design, waarbij aan de hand van dossierinformatie wordt teruggegaan in de tijd en achteraf bepaald wordt of gezinnen wel of niet een familienetwerkberaad hebben gehad) kwam naar voren dat familienetwerkberaden leidden tot minder meldingen van kindermishandeling en minder en kortere uithuisplaatsingen.

Echter, in studies met een prospectief design (een sterker design, waarbij op voorhand wordt bepaald welke gezinnen wel of geen familienetwerkberaad krijgen en onderzoeksgegevens voor en na het inzetten van de werkwijze verzameld worden) werden tussen de werkwijzen geen verschillen gevonden wat betreft kindermishandeling en uithuisplaatsing.

Daarnaast werd gevonden dat familienetwerkberaden leidden tot meer en langere uithuisplaatsingen in gezinnen waarbij de kinderen ouder waren en in gezinnen behorend tot een minderheidsgroep.

In het algemeen kan op basis van deze overzichtsstudie geconcludeerd worden dat er, ondanks de brede implementatie van familienetwerkberaden in de jeugdzorg, maar weinig robuust onderzoek beschikbaar is naar de effectiviteit hiervan. Beschikbare studies zijn veelal van lage kwaliteit, door het retrospectieve design, doordat er alleen gebruik wordt gemaakt van dossierinformatie of van niet-gevalideerde onderzoeksinstrumenten, en/of vanwege beperkte informatie over de uitvoering van de methodiek.

Voor de veiligheid van kinderen in de jeugdzorg is het daarom noodzakelijk dat er meer robuust onderzoek naar de effectiviteit van familienetwerkberaden wordt uitgevoerd (Dijkstra et al. 2016).

\section{De onderzoeksopzet van de eigen studie}

Vanwege de beperkingen van eerder gepubliceerd onderzoek naar de effectiviteit van de EKC, werd door de onderzoeksgroep Forensische Orthopedagogiek van de Universiteit van Amsterdam besloten om een nieuwe studie op te zetten naar dit onderwerp. Het onderzoek werd gesubsidieerd door ZonMW en startte in januari 2014. Het werd uitgevoerd in samenwerking met de Eigen Kracht Centrale (aanbieder van EKC's) en Jeugdbescherming Regio Amsterdam. In totaal gaven 328 gezinnen die verwezen werden naar Jeugdbescherming Regio Amsterdam toestemming voor deelname aan het onderzoek. Er werd gekozen voor een design waarbij per toeval werd bepaald of gezinnen wel of geen EKC kregen aangeboden (randomized controlled trial). Door de random toewijzing was de kans het grootst dat de groep gezinnen met en zonder EKC-aanbod bij de start van het onderzoek gelijk aan elkaar waren. Dan zijn eventuele verschillen tussen de groepen in uitkomsten na afloop toe te schrijven aan de verschillende werkwijzen. De gezinnen werden gerandomiseerd (ratio 2:1) voor de experimentele groep (EKC-groep; $N=229$ ) of de controlegroep $(N=99)$. In beide groepen werd gestart met GGW (Generiek Gezinsgericht Werken; inmiddels Intensief Systeemgericht Casemanagement), een methodiek waarbij de gezinsmanager samen met het gezin (en een eventueel netwerk) een plan maakt om problemen binnen het gezin aan te pakken. Het verschil tussen de experimentele groep en de controlegroep zit in de manier waarop het plan gemaakt en uitgevoerd wordt. In de experimentele groep werd getracht 
een hulpverleningsplan te maken door middel van een EKC, terwijl in de controlegroep het hulpverleningsplan werd gemaakt volgens de reguliere werkwijze van GGW.

Het onderzoek kende vijf meetmomenten: een voormeting bij aanvang van de hulpverlening (T1), een nameting één maand na totstandkoming van een EKC-plan of regulier hulpverleningsplan (T2), een nameting na drie maanden (T3), een nameting na zes maanden (T4) en een afsluitende nameting twaalf maanden na totstandkoming van ofwel het EKCplan ofwel het reguliere hulpverleningsplan (T5). De gegevens zijn verzameld met behulp van vragenlijsten die zijn ingevuld door ouders, gezinsmanagers en EK-coördinatoren. Daarnaast is er dossieronderzoek verricht voor aanvullende informatie. De effectiviteit van de EKC is onderzocht in termen van kindveiligheid, inzet van professionele zorg, empowerment en sociale steun. Aanvullend is informatie verzameld over gezinskenmerken en over hoe het tot een Eigen Kracht-conferentie kwam (Asscher et al. 2014).

\section{Hoe het tot een EKC komt in de jeugdzorg}

Allereerst werd aandacht besteed aan de vraag hoe het tot een EKC komt in de jeugdzorg. Voor de vraagstelling van deze studie zijn alleen de gezinnen onderzocht waar een EKC werd aangeboden $(N=229)$. Er werd gemonitord welk percentage van de gezinnen het aanbod om een EKC in te zetten accepteerde en welk percentage van de gezinnen tot een conferentie kwam. Indien het proces gestaakt werd, zijn de redenen hiervoor opgevraagd bij verschillende informanten, namelijk ouders, gezinsmanagers en EK-coördinatoren. Tevens is onderzocht of gezinskenmerken (waaronder demografische kenmerken, ouderkenmerken of gezinskenmerken) van invloed waren op de kans dat een conferentie daadwerkelijk doorgang vond.

Van de $N=229$ gezinnen die een aanbod is gedaan voor het organiseren van een EKC accepteerden 137 gezinnen dit aanbod (60 procent). Van deze 137 gezinnen sloten 62 gezinnen ( 45 procent van de gezinnen die het aanbod voor een EKC accepteerden) het proces af met het organiseren van een conferentie. In totaal heeft dus 27 procent van de gezinnen waar een EKC werd voorgesteld het proces tot en met de conferentie doorlopen. Redenen van gezinnen om niet in te gaan op het aanbod van een EKC en om geen conferentie te organiseren, zoals verwoord door de gezinnen en de gezinsmanagers, waren voornamelijk gebrek aan motivatie, de noodzaak van andere hulp in plaats van een EKC en dat er sprake was van een vechtscheiding. Een deel van de gezinsmanagers gaf daarnaast aan zelf geen meerwaarde te zien in een EKC, bijvoorbeeld omdat het niet het juiste moment in het begeleidingsproces was of omdat de maatschappelijke problemen van het gezin niet konden worden opgelost met het netwerk. Gezinnen waarvan de ouders gescheiden of uit elkaar waren, hadden minder kans om tot een conferentie te komen, terwijl gezinnen waarbij sprake was van kindermishandeling in het gezin juist een grotere kans hadden om tot een conferentie te komen. Geconcludeerd is dat het slechts bij een klein deel van de gezinnen (27 procent) daadwerkelijk tot een conferentie komt wanneer een EKC standaard wordt aangeboden in het begin van het hulpverleningstraject.

De genoemde gezinskenmerken verklaren deels de uitval in de voorbereidingsfase. De redenen die ouders noemen, suggereren daarnaast dat het doel van een EKC in de jeugdzorg niet altijd helder is, wat de kans vergroot dat gezinnen het aanbod weigeren. Daarnaast kan de attitude van de gezinsmanager een rol hebben gespeeld bij de hoge uitval. Hoewel de attitude van gezinsmanagers tegenover EKC's niet systematisch is onderzocht in deze studie, gaf toch een klein percentage van de gezinsmanagers aan dat zij negatief tegenover de EKC 
staan. Deze negatieve houding kan een rol hebben gespeeld bij hoe de gezinsmanager het aanbod van een EKC heeft gepresenteerd aan ouders (Dijkstra et al. 2017).

\section{De effectiviteit van de EKC in de jeugdzorg}

$\mathrm{Na}$ de analyse van de manier waarop het tot een EKC komt, is onderzoek verricht naar de effecten van een EKC op de korte en lange termijn. Deze effecten zijn onderzocht in termen van

1. kindveiligheid (veiligheidsscore, meldingen van / risico op kindermishandeling, uithuisplaatsing, ondertoezichtstelling);

2. inzet van professionele zorg (duur van het jeugdzorgtraject, inzet van professionele begeleiding en behandeling door zorgaanbieders);

3. empowerment van ouders;

4. toename van betrokkenheid van het bredere sociale netwerk van het gezin (aantal steunbronnen en ervaren sociale steun).

Voor deze studie werden data van de gehele onderzoeksgroep $(N=328)$ 1, 3, 6 en 12 maanden na totstandkoming van een plan onderzocht op effecten van een EKC. Tevens is de mogelijke invloed van gezinskenmerken op de effectiviteit van een EKC onderzocht. Als laatste is onderzocht in hoeverre een EKC daadwerkelijk werd uitgevoerd zoals bedoeld en of dit gerelateerd was aan de effecten.

Uit de resultaten komt naar voren dat een EKC even effectief is als de reguliere werkwijze voor het verbeteren van de kindveiligheid (veiligheidsscore, aanwijzingen voor / risico op kindermishandeling) en voor het vergroten van de ervaren sociale steun. Wel komt naar voren dat in de EKC-groep meer kinderen uit huis waren geplaatst. Op de korte termijn (bij follow-up na 1, 3 en 6 maanden) resulteerde de inzet van een EKC in een langere duur van het jeugdzorgtraject. Dit werd waarschijnlijk veroorzaakt door de langere periode die gezinnen in de EKC-groep nodig hadden om tot een plan te komen. Op de lange termijn (na 12 maanden) is gevonden dat gezinnen in de EKC-groep meer gebruikmaakten (zij het marginaal) van professionele begeleiding en behandeling door zorgaanbieders dan gezinnen in de controlegroep. Hoewel positieve effecten van EKC's zijn gevonden voor wat betreft empowerment en sociale steunbronnen waren deze effecten klein en inconsistent in de tijd. Gezinskenmerken, zoals etniciteit, de gezinssamenstelling, het opleidingsniveau van ouders, een lichte verstandelijke beperking en de aanmeldreden, bleken niet van invloed op de resultaten, wat suggereert dat de effectiviteit van de EKC niet verschilt voor verschillende subgroepen. Van de 62 conferenties resulteerden er 60 in een EKC-plan. Na zes maanden werkte minder dan de helft van deze gezinnen nog met het plan, wat resulteerde in een lage score voor implementatie. Hogere scores op implementatie waren gerelateerd aan een hoger aantal steunbronnen op alle meetmomenten. Dus: hoe meer stappen van het EKCproces doorlopen werden (van aanbod tot aan conferentie), hoe meer steunbronnen werden gerapporteerd door het gezin. Echter, gezinnen met een hogere implementatiescore, dus gezinnen die meer stappen van het EKC-proces doorliepen, voelden zich zes maanden na het tot stand komen van een hulpverleningsplan minder competent en makten marginaal meer gebruik van professionele begeleiding en behandeling door zorgaanbieders in vergelijking met gezinnen die al vroeg in het EKC-proces afhaakten.

Geconcludeerd is dat een EKC over het algemeen niet effectiever is dan de reguliere werkwijze. Hoewel kleine positieve effecten werden gevonden voor de meer secundaire uitkomstmaten als empowerment en sociale steun, werd de primaire uitkomstmaat, namelijk het verbeteren van de kindveiligheid, niet beter bereikt met de inzet van een EKC dan met 
de reguliere werkwijze. De langere tijd die gezinnen in de EKC-groep nodig hadden om tot een hulpverleningsplan te komen, resulteerde daarnaast niet in snellere toename van kindveiligheid, waardoor gezinnen in de EKC-groep gemiddeld langer gebruikmaakten van jeugdzorg.

Een opvallende uitkomst in de huidige studie is het verschil in empowerment dat werd gevonden binnen de EKC-groep, namelijk dat gezinnen die het aanbod van een EKC direct afsloegen en gezinnen die een EKC weigerden na een informatief gesprek met een EKcoördinator, betere resultaten lieten zien op empowerment dan gezinnen die verder in het EKC-traject kwamen of die een EKC-plan maakten. Het lijkt erop dat deze eerste groep gezinnen profiteert van de denkwijze van de EKC en het idee dat zij een keuze hebben wat betreft de manier waarop het hulpverleningsplan opgesteld wordt zonder dat zij het proces tot conferentie en het EKC-plan zelf doorlopen. Dit suggereert dat het volledig afronden van een EKC-traject niet noodzakelijk is voor het stimuleren van eigen kracht (Dijkstra et al. 2018a).

\section{De kosteneffectiviteit van de EKC in de jeugdzorg}

In de laatste studie van het proefschrift is de kosteneffectiviteit van de EKC onderzocht, waarbij data zijn gebruikt van een gedeelte van de totale onderzoeksgroep $(N=69)$. Bij kosteneffectiviteit wordt gekeken naar de verhouding tussen de financiële inspanningen en de opbrengsten (resultaten) van de methodiek. In dit geval werden de opbrengsten uitgedrukt in termen van kindveiligheid, empowerment en sociale steun. In lijn met de resultaten van de effectstudie, waarbij de totale onderzoeksgroep is onderzocht, zijn er geen verschillen tussen de EKC-groep en de controlegroep gevonden voor wat betreft het risico op kindermishandeling en sociale steun. Voor wat betreft empowerment is gevonden dat zes maanden na totstandkoming van een plan ouders in de EKC-groep zich meer empowered voelden dan ouders in de controlegroep. Echter, dit positieve effect was niet meer aanwezig op de lange termijn.

Voor wat betreft de zorgkosten is gevonden dat zes maanden na totstandkoming van een plan de gemiddelde zorgkosten in de EKC-groep ( $€ 13.422,08)$ niet significant hoger waren dan de gemiddelde zorgkosten in de controlegroep ( $€ 11.813,83$ ). Ook twaalf maanden na totstandkoming van een plan waren de gemiddelde zorgkosten in de EKC-groep (€ 20.192,31) niet significant hoger dan de gemiddelde zorgkosten in de controlegroep ( $€ 17.925,31$ ). Kosteneffectiviteitsanalyses lieten zien dat wat betreft kindermishandeling, empowerment en sociale steun op zowel de korte als de lange termijn een EKC niet kosteneffectiever is dan de reguliere werkwijze. Een EKC resulteerde in iets grotere effecten, maar ook in hogere zorgkosten. De kans dat de EKC een kosteneffectieve methodiek is ten opzichte van de reguliere werkwijze was kleiner dan 30 procent.

Tevens is onderzocht of de kosteneffectiviteit van een EKC verschilt voor de verschillende fases waarin een gezin kon uitvallen in het EKC-traject. Zowel voor kindermishandeling, empowerment en sociale steun zijn op beide meetmomenten vergelijkbare resultaten gevonden. De EKC-aanpak was, in vergelijking met de reguliere werkwijze, wel kosteneffectief bij gezinnen die niet ingingen op het aanbod om een EKC in te zetten en gezinnen die stopten na een informatief gesprek met een EK-coördinator. Echter, gezinnen die stopten gedurende de voorbereidingsfase van de EKC en gezinnen die de EKC afrondden, laten juist tegenovergestelde resultaten zien. Op zowel de korte als de lange termijn laat deze groep minder sterke effecten en hogere kosten zien dan de controlegroep, waardoor de EKCaanpak niet kosteneffectief blijkt ten opzichte van de reguliere werkwijze. Omdat deze 
resultaten overeenkomen met de resultaten in de effectstudie wat betreft de invloed van implementatie op de effectiviteit lijkt het erop dat gezinnen meer profiteren van enkel het aanbod van EKC (en mogelijk het gedachtegoed) dan van de conferentie an sich (Dijkstra et al. 2018b).

\section{Conclusie}

Op basis van dit promotieonderzoek kan geconcludeerd worden dat er weinig bewijs is voor de effectiviteit van EKC in de jeugdzorg.

In lijn met eerder robuust onderzoek is gevonden dat EKC niet effectiever is dan de reguliere werkwijze van jeugdzorg om tot een hulpverleningsplan te komen in termen van kindveiligheid en inzet van professionele zorg. Hoewel positieve resultaten zijn gevonden voor empowerment en sociale steun zijn deze effecten klein en inconsistent in de tijd.

Ook wegen deze positieve resultaten niet op tegen de langere duur van het jeugdzorgtraject en de extra inzet (zij het marginaal) van professionele begeleiding en behandeling van zorgaanbieders. Hierdoor blijkt EKC geen kosteneffectieve methodiek in de jeugdzorg.

Naast de geringe effectiviteit kan worden geconcludeerd dat de implementatie van EKC anders is dan beoogd. Het lage percentage gezinnen dat tot een conferentie komt, de redenen voor uitval in het proces en de langere periode die gezinnen nodig hebben om een plan van aanpak te maken, suggereren dat het doel van de EKC in de jeugdzorg mogelijk nog niet helder genoeg is en dat de implementatie niet gepaard gaat met voldoende begeleiding en richtlijnen. Op basis van de resultaten in dit proefschrift rijst daarom de vraag of de manier waarop de EKC wordt ingezet in de jeugdzorg de juiste is.

\section{Literatuur}

Asscher, J.J., Dijkstra, S., Stams, G. J.J.M., Deković, M., \& Creemers, H.E. (2014). Family group conferencing in youth care: characteristics of the decision making model, implementation and effectiveness of the Family Group (FG) plans. BMC Public Health, 14(1), 154.

Denktank Transformatie Jeugdstelsel (2014). Van beter naar minder: bouwstenen voor de transformatie van het jeugdstelsel. Utrecht: Nederlands Jeugdinstituut.

Dijkstra, S., Creemers, H. E., Asscher, J. J., Deković, M., \& Stams, G. J. J. M. (2016). The effectiveness of Family Group Conferencing in youth care: a meta-analysis. Child Abuse \& Neglect, 62, 100-110.

Dijkstra, S., Creemers, H.E., Asscher, J.J., Deković, M., \& Stams, G.J.J.M. (2017). Family Group Conferencing in youth care: which families are most likely to organize a Family Group conference after referral in youth care? Children and Youth Services Review, 83, 255-263.

Dijkstra, S., Asscher, J. J., Deković, M., Stams, G. J. J. M., \& Creemers, H.E. (2018a). A randomized controlled trial on the effectiveness of Family Group Conferencing in child welfare: effectiveness, moderators and level of FGC completion. Child Maltreatment, 24(2), 137-151. https://doi.org/10. $1177 / 1077559518808221$.

Dijkstra, S., Creemers, H.E., Steensel, F.J.A. van, Deković, M., Stams, G.J.J.M., \& Asscher, J.J. (2018b). Cost-effectiveness of Family Group Conferencing in child welfare: a controlled study. BMC Public Health, 18(1), 848.

Frost, N., Abram, F., \& Burgess, H. (2014). Family group conferences: context, process and ways forward. Child \& Family Social Work, 19(4), 480-490.

Hoek, M. (2010). Eigen Kracht: een andere visie op het verlenen en krijgen van hulp. Utrecht: Nederlands Jeugdinstituut.

MacLeod, J., \& Nelson, G. (2000). Programs for the promotion of family wellness and the prevention of child maltreatment: a meta-analytic review. Child Abuse \& Neglect, 24, 1127-1149. 
Pagee, R. van (2012). Family group conference renews the relationship between citizens and the government. In R. Clarijs \& T. Malmberg (red.), The quiet revolution: aggrandising people power by Family Group Conferences. Amsterdam: SWP.

Dr. Sharon Dijkstra is werkzaam als orthopedagoog en cognitief gedragstherapeut in opleiding bij Youz, specialistische kinder- en jeugdpsychiatrie. Hiervoor werkte zij als promovenda aan de Universiteit van Amsterdam, afdeling Forensische Orthopedagogiek.

Dr. Hanneke Creemers is universitair docent aan de Universiteit van Amsterdam, afdeling Forensische Orthopedagogiek.

Prof. dr. Jessica Asscher is hoogleraar aan de Universiteit Utrecht, afdeling Child and Adolescent Studies en universitair hoofddocent aan de Universiteit van Amsterdam, afdeling Forensische Orthopedagogiek.

Prof. dr. Maja Deković is hoogleraar aan de Universiteit Utrecht, afdeling Clinical Child and Family Studies.

Prof. dr. Geert Jan Stams is hoogleraar aan de Universiteit van Amsterdam, afdeling Forensische Orthopedagogiek. 